\title{
ISO 14001:2015: An Improved Tool for Sustainability
}

\author{
Luis Miguel Ciravegna Martins da Fonseca \\ ISEP-IPP, School of Engineering Polytechnic of Porto (Portugal)
}

$\underline{\operatorname{lm} f @ \text { isep.ipp.pt }}$

Received: November 2014

Accepted: January 2015

\section{Abstract:}

Purpose: ISO 14001 is an International Standard of worldwide acceptance based on the concept that better environmental performance can be achieved when environmental aspects are systematically identified and managed giving a major contribution to Sustainability, through pollution prevention, improved environmental performance and complying with applicable laws. This paper aims to discuss the Sustainability approach through the use of Environmental Management Standards (EMS), the results achieved by organizations that implement and certify those EMS and a special focus on the current process of ISO 14001:2015 revision and the logic behind it.

Design/methodology/approach: Revisiting the concept of Sustainability, the status of ISO 14001, its application benefits and certification and the revision process of ISO 14001:2015 and its expected outcomes are discussed.

Findings: This is one of the first attempts to analyze, within the Sustainability framework, the status of the revision of the future ISO 14001:2015 International Standard that will respond to the latest trends and is expected to further improve Environmental performance. It will impact the work of many People and Organizations worldwide, try to responder to both practitioners and academicians inputs and also ensure it is compatible with other management system standards such as ISO 9001. 
Research limitations/implications: Since the revision standard is not yet finished some changes might happen and some of the remarks expressed in this paper might not be consensual within the Environmental Community. In addition, there are still open questions not yet solved by research that could be revisited when the future ISO 14001:2015 is implemented and the conclusions should be an incentive for future research work.

Practical implications: There will be a 3 year transition process for the ISO 14001:2015 certification and major benefits like Environmental Management Systems with less emphasis on documentation and new/reinforced approaches as consideration of organizational context and (relevant) Stakeholders, risk based thinking, life cycle perspective and more emphasis on improving environmental performance.

Social implications: The ISO 14001:2015 revision will have major impacts on the more than 300.000 worldwide certified organizations and on the many professionals that work with it.

Originality/value: Although 14001:2015 is not yet finished the author thinks organizations will have new tools for environment performance enhancement that also try to answer stakeholders inputs and some of the open research issues concerning EMS implementation, certification and outcomes. The main question is how far ISO/TC 207 can go without alienating the "traditional" user. Major changes should include understanding of the organization's context in order to better manage risk, emphasis on relevant stakeholders, leadership to promote environmental management, the introduction of the concept of life cycle perspective and a shift towards improving environmental performance.

Keywords: sustainability; ISO 14001 revision; standardization; environmental management systems

\section{Introduction: What is Sustainability?}

Sustainable development is development that meets the needs of the present without compromising the ability of future generations to meet their own needs" in the definition of the Brundtland Commission Report (1987). This implies the simultaneous search for profitable economic development, social progress and equity and respect for the environment (Elkington, 1997) while creating value for shareholders, customers, workers and the society at large. This also requires a multidisciplinary and systemic approach since the global nature of the issues require that economic actors, governments, public and private organizations and citizens be actors in this process. There is no consensus concerning the concept of Sustainability (nature, motivations, and impacts) and the results of relevant programs on organizational performance. However, the research of literature review allows us to conclude that most definitions take into 
consideration, the economic, social and environmental dimensions (Fonseca, 2012). One of the main theories supporting the business case for Sustainability is Stakeholder Theory (Freeman, 1984) by focusing on the importance of a firm's relationships with critical stakeholders that may lead to better performance, as organizations that integrate business and societal considerations create value for their stakeholders. Accordingly to ISO 14001:2015 DIS (Draft International Standard), achieving a balance between environmental, social and economic subsystems within the global system is considered essential in order to meet the needs of the present without compromising the ability of future generations to meet their needs. This concept of the 'three pillars' of sustainability is the goal of sustainable development. This has led organizations to adopt a systematic approach to Environmental Management by implementing Environmental Management Systems with the aim to contribute to the 'environmental pillar' of sustainability and ultimately to better organizational performance and increased stakeholder satisfaction (Fonseca, 2012).

\section{The ISO 14001 International Standard}

Today there are considerable international standards that aim to systematize the implementation of business management systems. Two series of standards issued by the International Organization for Standardization (ISO) had attained major impact worldwide: the ISO 9000 series, related to the implementation of Quality Management Systems (QMS) and the ISO 14000 series, related to the implementation of Environmental Management Systems, (EMS). ISO 14001 is an International Standard of worldwide acceptance based on the concept that better environmental performance can be achieved when environmental aspects are systematically identified and managed giving a major contribution to Sustainability, through pollution prevention, improved environmental performance and complying with applicable laws. ISO 14001 can therefore be considerable a relevant contribution for Environmental Sustainability as stated in the "introductory" and "scope" sections of ISO/DIS 14001:2015 and supported by some academic authors (www.iso.org; Sebhatu \& Enquits, 2007). According to ISO, Rio de Janeiro's 1992 conference put sustainable development clearly on the political agenda. And today the issue is more relevant than ever. ISO claims to have a comprehensive range of standards that can help businesses and organizations all over the world make progress in the three pillars of sustainable development - the environment, economy and society, being the Environmental Management of ISO 14000 family of International Standards the main focus or the Environmental pillar of Sustainability. From the academic side, Sebahatu and Enquist (2007), based on case study analysis claim that "ISO 14001 Environment Management Systems is not only a system for environmental performance, but can also be used as a driving force for Sustainable Development and value creation in a radical change process aimed at quality improvement". The proposed ISO 14001:2015 DIS version clearly states that "This International Standard specifies the requirements of an environmental 
management system for organizations seeking to establish, implement, maintain and continually improve a framework with the aim to manage its environmental responsibilities in a manner that contributes to the 'environmental pillar' of sustainability".

In 2013, ISO/TC 207/SC 1 (www.iso.org) conducted a survey on ISO 14001 covering a range of potential areas for continual improvement. The survey was issued in 11 languages through national member bodies, and gathered an unprecedented response level with close to 5000 participants in 110 countries worldwide. Accordingly to ISO 14001 Continual Improvement Survey Executive Summary (2013, accessed at www.iso.org) the motivations reported for adopting this International Standard, based on user rankings of factors influencing their adoption of the standard are:

- Commitment to environmental protection/conservation.

- Reduction of risk of adverse environmental impact.

- Primary influences related to business management including customer requirements and public image.

- Also more than half of the respondents indicated value for business in integration with other management standards applied by the organization (such as ISO 9001, ISO 50001, ISO 26000, and OHSAS 18001).

Some of the Survey major conclusions can be highlighted as follows:

- The Value of ISO 14001 for Users: for environmental management, responses from users suggest that organizations have realized significant value from ISO 14001 in terms of meeting legal requirements, improving environmental performance, and enhancing management commitment and stakeholder engagement. Close to $75 \%$ of participants indicated 'high' or 'very high' value for meeting legal requirements and improving the organization's environmental performance, while more than $60 \%$ indicated 'high' to 'very high value' for management commitment and employee engagement. Overall, $85 \%$ or more indicated at least a moderate value in all categories except improvement in supplier environmental performance where $63 \%$ of user responses indicated at least moderate value in this area.

- Responses from users also suggest that ISO 14001 has provided considerable value for business management, most notably for meeting stakeholder requirements, improving public image, achieving strategic objectives, and integrating with business management systems. More than half of participants indicated 'high' to 'very high' value, and more than $80 \%$ indicated at least a moderate value in these areas. Furthermore, $78 \%$ and 
$63 \%$ of responses indicated at least a moderate value in terms of providing a competitive advantage and financial benefit, respectively.

From an academic point of view there are several works that have studied the impacts of ISO 14001 EMS and conclude that organizations have advantages of implementing and using these standards (Mori \& Welch, 2008; Fortunski, 2008; Vries, Bayramoglu \& Wiele, 2012). More recently studies by Tari, Molina-Azorín and Heras (2012) also suggest that ISO 14001 has clear benefits on organizational, operational, people and customer results and that the effects on financial performance are inconclusive. However this paper does acknowledge that other studies have reached different conclusions and suggests that variables related to the reasons for certification should be included in future research studies. Also accordingly to Yin and Schmeidler (2009) standardized management systems may be implemented in very different ways depending on organizations, which might explain the heterogeneous performance of these standardized systems and these authors stress that the studies of the impacts of ISO 14001 certification have largely neglected this phenomenon. In light of these conclusions the author will like to add his own personal perspective on the issue, supported on more than 20 years' experience in the certification business:

- There are considerable methodological differences and control variables on studies concerning ISO 14001 certification impacts.

- We need to understand the conditions under wish ISO 14001 EMS certification benefits organizational environmental and overall performance.

- Certification to ISO 14001 should be a result of a well implemented EMS, not just "certification".

- ISO 14001:2004 (and future ISO 14001:2015 even more) do have some challenges for the auditors, e.g., how much improvement is enough? Environmental applicable laws are not the same in all countries, so level of compliance and EMS performance might change from country to country. Additionally there is some variation between Certification Bodies approaches and practices, in relation to global coverage, level of expertise, audit approaches and rigor.

- In summary certification is indeed a measure of EMS implementation intensity but we need to take into consideration how variations in EMS implementation may affect performance results.

These considerations fully support Heras and Boiral (2013) position that "further critical and rigorous empirical studies are necessary in order to analyze the real perceptions of the various stakeholders (consumers, managers, suppliers, intermediary clients, workers and public administration) regarding the adoption of meta-standards and their effects". 


\section{ISO 14011 Certification Evolution}

According to ISO Survey 2013 (www.iso.org/iso/iso-survey) until the end of December 2013, at least 301,647 ISO 14001:2004 certificates had been issued in 171 countries, four more than in the previous year, representing a growth of $6 \%$ in certificates number $(+16,993)$ from previous year. Although certification is not compulsory in many situations, the number of ISO 14001 certified EMS available through ISO survey 2013 can be a good proxy to evaluate the dissemination of this International Standard (Terlaak \& King, 2006).

The top three countries for the total number of certificates issued were China, Italy and Japan, while the top three for growth in the number of certificates in 2013 were China, Italy and India. Figure 1 (source ISO Survey, 2013, available at www.iso.org) summarizes the evolution of ISO 14001 certifications worldwide:

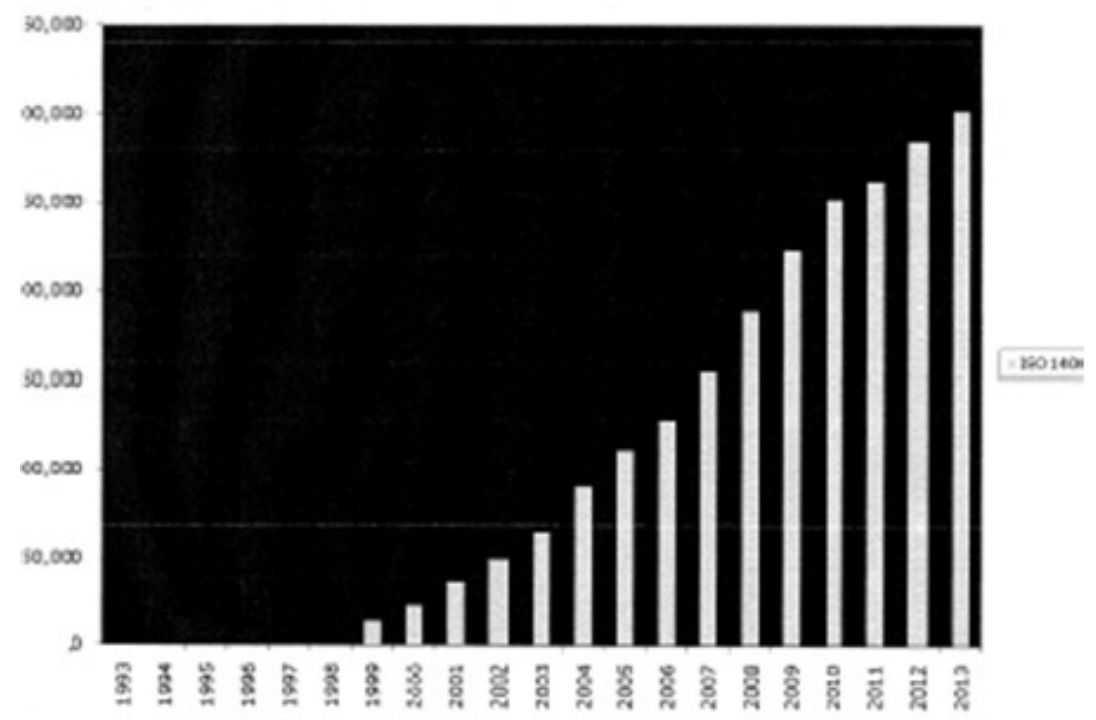

Figure 1. ISO 14001 certifications worldwide (ISO Survey 2013)

Several authors have been studying this growth phenomena (e.g., Corbett \& Kirsch, 2001; Poksinska, Dahlgaard \& Eklund, 2003; Gonzalez-Benito \& Gonzalez-Benito, 2005; Viadiu, Casadesus \& Heras, 2008, Mori \& Welch, 2008; Fortunski, 2008; Vries, Bayramoglu \& Wiele, 2012, Tari et al., 2012). Conclusions appoint to major perceived benefits in the improved relations with stakeholders and in marketing advantages. Some also report cost reductions (e.g., less consumptions and less emissions and waste) better environmental results and organizational improvements (ACCREDIA-CESQA, 2013, accessed at www.accredia.it). The standard requires companies to set their environmental policy and objectives themselves and the identification of environmental aspects and compliance with the law are usually stated as important and requiring most effort. However, as already stated by Heras and Boiral (2013), future research should explore the sources of variation in the quality of implementation of 
meta-standards in cross-country studies with different cultures, political environments and economic performance.

Another factor to take in consideration is that some countries have incentive plans supporting EMS implementation and certification, while others do not, which might be a good reason to explain the intensity level of EMS certification between some countries.

Also, according to some authors, the introduction of EMS as short-term measures in order to gain entry into global market will not ensure environmental sustainability. Yin and Ma (2009) study on manufacturing firms in China, found that ISO 14001 certification was merely used as passport to entry into advance market rather than the expected improve environmental performance. If the way organizations do things do not changes, the results will not improve and the meaning of a certificate will lose considerable value. In general, studies have found the internal motivations led to better results than external motivations (Tarí et al., 2012) but there are control factors (e.g., industry size and type, applicable environmental laws and cultural issues) and other dimensions that should be investigated like the way EMS are interpreted and implemented (Christman \& Taylor, 2006, Yin \& Schmeidler, 2009) and the time delay between implementation and improved results. And in fact some authors (e.g., Corbett and Young, 2008) considering the impact of meta-standards like ISO 14001, find it surprisingly there is no more scholarly research on most of those standards.

Concerns on the auditability and the value of certification (e.g., expressed by Boiral \& Gendron, 2011) are address by ISO International Standard ISO/IEC 17021:2011 - Conformity assessment Requirements for bodies providing audit and certification of management systems. In conjunction with ISO 19001 - Guidelines for quality and/or environmental management systems auditing - International Standard, that aims for reduction of the variability of Certification Bodies practices and Auditors approaches and performances, especially for Accredited Certification Bodies within the International Accreditation Forum umbrella (www.iaf.org).

\section{The ISO 14001:2015 Revision}

\subsection{The ISO 14001:2015 Revision Process}

ISO has a Directive governing the publication of standards. All full ISO standards require to be reviewed every 5 years (ISO Directive Part $1, \mathrm{Cl} .2 .9 .1$ ). The review can confirm that there is no change, but normally not.

The aims of the revisions are to ensure the standards are updated and relevant for the marketplace. The future ISO 14001:2015 will respond to latest trends and ensure it is 
compatible with other management system standards such as ISO 9001 . The revision of ISO International standards follows a process that can be summarized as follows (www.iso.org):

- WD (Working Draft) -> CD (Committee Draft) -> DIS (Draft International Standard -> FDIS (Final International Standard) -> IS (International Standard that is the final revised standard). The proposed ISO 14001:2015 International Standard is presently at DIS stage, the fourth stage of a six stage process and those interested can still submit feedback to the experts of ISO TC 207 Technical Committee. Once all comments have been considered and the draft is approved, it will move into the Final Draft (FDIS) stage before publication of the revised ISO 14001:2015 International Standard that is expect to happen by the end of 2015 (Source ISO TC 207, www.iso.org). Accordingly to ISO/TC 207/SC 1 the agreed scope of the revision is based on the High Level Structure (HLS) for Management System Standards (MSS) and its identical text, common terms and core definitions (referred to as 'Annex SL Structure'). It should also take into consideration the final report of the ISO/TC 207 SC 1 "Future Challenges for EMS" Study Group; ensure the maintenance and improvement of the basic principles of ISO 14001: 2004, and also the retention and improvement of its existing requirements.

\subsection{Major Differences Expected for the ISO 14001:2015 Edition}

Based on the present DIS version, we can expect the following major changes to ISO 14001:2015 when compared with the 2004 version (The DIS contains both new elements and existing elements that are changing):

- ISO 14014:2015 will follow the 'Annex SL Structure': 4: Context of the organization, 5: Leadership, 6: Planning, 7: Support, 8: Operation, 9: Performance evaluation, 10: Improvement. This is consistent with academic studies that recommend integration of Management System Standards (Karapetrovic, 2002; Zeng, Shi \& Lou, 2007).

- It introduces two new clauses relating to the context of the organization, which require the organization to determine the issues and requirements that can impact on the planning of the environmental management system and can be used as an input into its development. Environmental management importance within the organization strategic planning has considerable increased. Organizations should understand the context they operate to identify and take into consideration opportunities for the benefit of both the organization and the environment. Particular focus is on issues or changing circumstances related to the needs and expectations of (relevant) interested parties (including regulatory requirements) and local, regional or global environmental conditions that can affect, or be affected by, the organization. Once identified as a priority, actions to mitigate adverse risk or exploit beneficial opportunities are integrated in the operational planning of the environmental management system (ISO 
TC 207, www.iso.org). It would be expected that organizations commit to proactive initiatives to protect the environment from harm and degradation, consistent with the context of the organization. These changes come to an answer both to practitioners' inputs trough ISO 2013 ISO/TC 207 Survey and to the inconsistency and open questions detected during literature review concerning the impacts and outcomes of EMS and its certification. Although it can be argued that this is supporting Yin and Schmeidler (2009) concerns with diversity in EMS implementation it is a need to adjust to EMSs to today's complex and dynamic world where so many different types of organizations coexist. This new clauses should also have positive contributions to Top Management and Employees motivation and involvement on EMS implementation leading to improved outcomes, which is also a key issue on literature review.

- A new clause has been added that assigns specific responsibilities for those in leadership roles to promote environmental management, in line with the previous remark on Top Management and Employees motivation and involvement In EMS implementation.

- Makes the adoption of a process approach in the implementation of an environmental management system more explicit (clause 4.4), and suggest the following Environmental Management Model presented in Figure 2 (source ISO/DIS 14001, www.iso.org) that links the Annex SL structure and the ISO 14001 PDCA mode (also in line with management systems integration and performance oriented management):

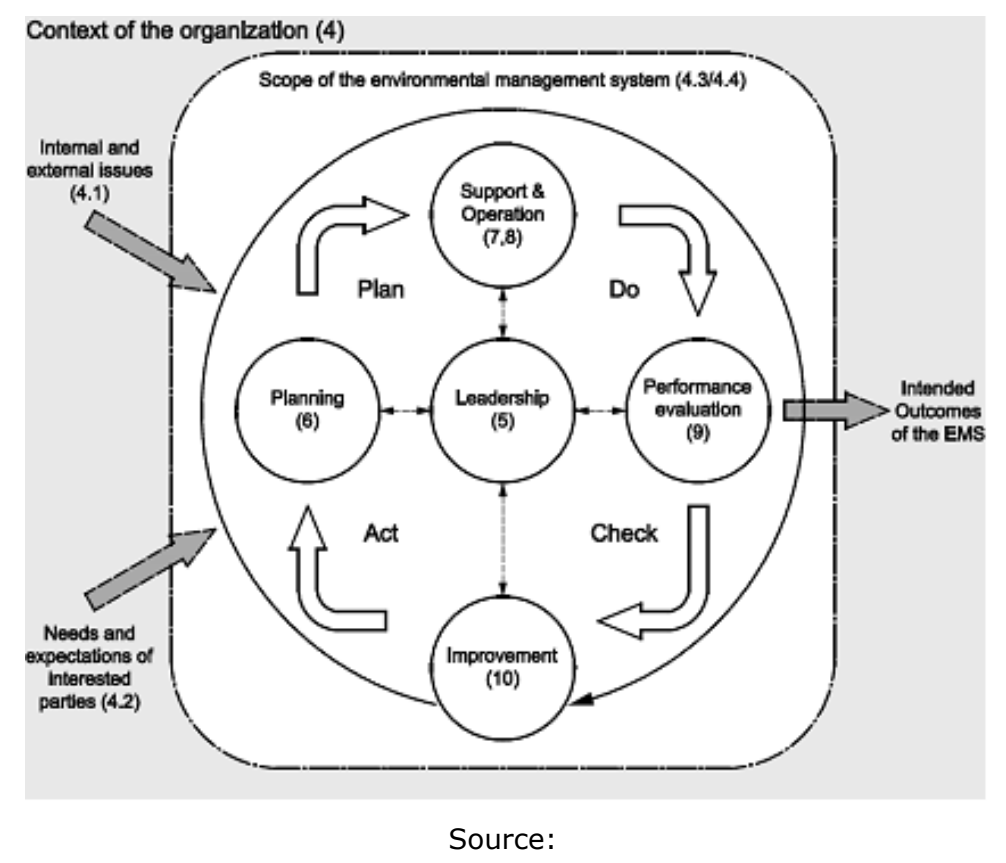

Figure 2. Environmental system model for ISO 14001:2015 (ISO DIS 14001, 2014) ISO DIS 14001 (available at www.iso.org) 
- More emphasis on performance improvement: accordingly with the organization's policy commitments it should reduce emissions, effluents and waste to levels set by the organization policy and objectives (e.g., clause 6.1.2 significant environmental aspects and clause 6.2 Environmental objectives and planning to achieve them). Given due implementation time, this could be an interesting research challenge for scholars to confirm if this aims has been realized (or not).

- Organizations will need to extend its control and influence to the environmental impacts associated with product use and end-of-life treatment or disposal. Although this does not imply a requirement to do a life cycle assessment, it introduces in fact the concept of life cycle perspective into the standard (clause 6.1.2), in line with the strong and more responsible stakeholder involvement (Fonseca, 2012).

- The development of a communications strategy (clause 7.4) with equal emphasis on external and internal communications has been added and needs to take into consideration needs to take into account information reporting required by regulatory agencies and the expectations of other interested parties. Reflecting the technological advances for managing information (e.g. digital with computers, tablets and even cloud based systems) the revision incorporates will use the term 'documented information', instead of 'documents' and 'records'. In line with ISO 9001 , the organization will retain the flexibility to determine when 'procedures' are needed to ensure effective process control.

\subsection{What Should Organization Do?}

- Stay tuned to what's happening with the revision of ISO 14001 and become familiar with concepts like "Risk-based thinking", "Relevant interested parties" and Life Cycle Assessment, study ISO 14001 DIS version (available through ISO web site, www.iso.org) and start working on understanding and incorporating the changes.

- Look regularly into www.iso.org since periodic updates will be made available by ISO/TC207/SC1. DIS will be followed by FDIS (Final Draft Standard) and IS (international Standard).

- Is your organization pleased with your present Environmental Management System? Does it integrates and supports your business well? Does it achieve the performance targets it is supposed to?

Depending on the answers, some organizations should consider the 2015 ISO 14001 revision as a great opportunity to review and reignite theirs EMS. If the system is working well, maybe just adjust it to the new ISO 14001:2015 changes. For certified organizations it is anticipated 
that the transition period will be three years from the publication date of the standard, so if the standard is published in September 2015, organizations will have up until September 2018 to transition. So, it is up to the organization when they actually wish to do the transition. If they feel that they are ready on the publication date of the standard, they can approach their certification body and ask to be certified against the new requirements from that date. However, if organizations feel they need time to develop their new system, they can transition any time between then and the 3 year plus publication date.

\section{Conclusions and Future Work}

ISO 14001 is an International Standard of worldwide acceptance aiming for better environmental performance and sustainability.

There is an increased adoption of International Standard EMS worldwide, being ISO 14001 the more relevant one and academics generally agree that its implementation may lead to several benefits like improved environmental performance, efficiency and profitability. Other benefits which have also merited great attention are improved image, improvement in customer satisfaction, improved staff results, improved competitive edge and improved relations with stakeholders (Tarí et al., 2012).

This can be achieved when environmental aspects are systematically identified and managed achieving pollution prevention, improved environmental performance and complying with applicable laws.

Accordingly to the review made, the future ISO 14001:2015 will try to respond to the following main issues identified also as relevant by scholars:

- Latest trends of an increasingly complex, demanding and dynamic environment and remains stable for the future.

- Outputs of the 2013 ISO/TC 207/SC 1 (www.iso.org) on ISO 14001 covering a range of potential areas for continual improvement, including concerns and questions from the academic world.

- Ensure it is compatible with other management system standards such as ISO 9001.

- Major changes should include understanding of the organization's context in order to better manage risk, emphasis on relevant stakeholders, Leadership to promote environmental management and a shift towards improving environmental performance.

- This should help organizations adapt the best approaches for its particular case aiming for improved environmental and organizational results. 
- Links with both supporting and open scientific literature review relevant issues has been made, leading to some additional research suggestions.

Since ISO 14001:2015 International Standard version is not yet approved, organizations should stay tuned to what's happening with the revision of ISO 14001 (some changes might still occur) and become familiar with concepts like "Risk-based thinking", "Relevant interested parties" and Life Cycle Assessment, study ISO 14001 DIS version and start working on understanding and incorporating the changes. And in the end "output does matters", environmental results should improve and positive contributions to a better world environment should happen.

Because some changes may still occur, this is a limitation for the analysis made in this article, which might be compensated for its innovation aspect. As for the future impacts of ISO 9001:2015, we will need time for its application for future scientific academic validation of the main purposes of this revision and its expected improvement environmental and organizational impacts, which is a major suggestion for future research. And as a final comment it is challenging that with such relevant open research questions, more scientific research should be done to close this knowledge gaps, including the impacts and outcomes of the future ISO 14001:2015 International Standard revision implementation and certification.

\section{References}

ACCREDIA-CESQA (2013, November). Indagine ISO 14001: Edizione 2013 dello studio ACCREDIA - Centro Studi Qualità Ambiene, Università di Padova, sulle organizzazioni italiane certificate. Retrieved from: http://www.accredia.it/UploadDocs/4415 Indagine ACCREDIA CESQA

Boiral, B., \& Gendron, Y. (2011). Sustainable development and certification practices: Lessons learned and prospects. Business Strategy and the Environment, 20, 331-347. http://dx.doi.org/10.1002/bse.701

Brundtland Commission Report (1987). Our Common Future. United Nations, WECED Report.

Corbett, C.J., \& Kirsch D.A. (2001). International diffusion of ISO 14000 certification. Production and Operations Management, 327-342.

Christmann, P., \& Taylor, G. (2006). Firm self-regulation through international certifiable standards: Determinants of symbolic versus substantive implementation. Journal of International Business Studies, 37, 863-883. http://dx.doi.org/10.1057/palgrave.jibs.8400231

Elkington, J. (1997). Cannibals with Forks. The Triple Bottom Line of $21^{\text {st }}$ Century Business. London: New Society Publishers C.J. 
Fonseca, L. (2012). Sustainability/Social Responsibility influence for organizational sustainable success, PhD Thesis, ISCTE-IUL, 2012.

Fortunski, B. (2008), Does the environmental management standard ISO14001 stimulate sustainable development? An example from the energy sector in Poland. Management of Environmental Quality, An International Journal, 19(2), 204-212.

Freeman, R.E.(1984). Strategic Management: A Stakeholder Approach. Boston: Pitman.

González-Benito, J., \& González-Benito, O. (2005). An analysis of the relationship between environmental motivations and ISO 14001 certification. British Journal of Management, 16(2), 133-48. http://dx.doi.org/10.1111/j.1467-8551.2005.00436.x

Heras, I.S, \& Boiral, O, (2013), ISO 9001 and ISO 14001: Towards a Research Agenda on Management System Standards. International Journal of Management Reviews, 15(1), 47-65. http://dx.doi.org/10.1111/j.1468-2370.2012.00334.x

ISO 14001:2004 (2004). Environmental management system: Requirements with guidance for use. Geneva, Switzerland: International Organization for Standardization.

ISO/DIS 14001 (2014). Environmental management system: Requirements with guidance for use. Geneva, Switzerland: International Organization for Standardization.

ISO International Organization for Standardization (2014). The ISO Survey 2013. Geneva: ISO Central Secretariat.

Karapetrovic, S. (2002). Strategies for integration of management systems and standards. TQM Magazine, 14(1), 61-67. http://dx.doi.org/10.1108/09544780210414254

Mori, Y, \& Welch, E.G. (2008). The ISO 14001 environmental management standard in Japan: Results from a national survey of facilities in four industries. Journal of Environmental Planning and Management, 51(3), 421-445. http://dx.doi.org/10.1080/09640560801979683

Poksinska, B., Dahlgaard, J.J., \& Eklund, J.A.E. (2003). Implementing ISO 14000 in Sweden: Motives, benefits and comparisons with ISO 9000. International Journal of Quality and Reliability Management, 20(5), 585-606. http://dx.doi.org/10.1108/02656710310476543

Sebhatu, S.P., \& Enquist, B. (2007). ISO 14001 as a driving force for sustainable development and value creation. The TQM Magazine, 19(5), 468-482.

http://dx.doi.org/10.1108/09544780710817883

Tarí, J.J., Molina-Azorín, J.F., \& Heras, I. (2012). Benefits of the ISO 9001 and ISO 14001 standards: A literature review. Journal of Industrial Engineering and Management, 5(2), 297-322. http://dx.doi.org/10.3926/jiem.488 
Terlaak, A., \& King, A.A. (2006). The effect of certification with the ISO 9000 quality management standard: A signaling approach. Journal of Economics Behavior \& Organization, 60, 579-602. http://dx.doi.org/10.1016/j.jebo.2004.09.012

Viadiu, F.M., Casadesus, M.F., \& Heras, I.S. (2008). ISO 14001 diffusion after the success of the ISO 9001 model. Journal of Cleaner Production, 16(8) 1741-1754.

http://dx.doi.org/10.1108/01443570610641648

Vries, H.J, de, Bayramoglu, D.K., \& Wiele, T., V, der, (2012). Business and Environmental impact of ISO 14001. International Journal of Quality and Reliability Management, 29(4), 425-435. http://dx.doi.org/10.1108/02656711211224866

Yin, H.T., \& Ma, C.B. (2009). International integration: a hope for a greener China? International Marketing Review, 26(3), 348-367. http://dx.doi.org/10.1108/02651330910960825

Yin, H., \& Schmeidler, P.J. (2009). Why do standardized ISO 14001 environmental management systems lead to heterogeneous environmental outcomes? Business Strategy and the Environment, 18, 469-486. http://dx.doi.org/10.1002/bse.629

Zeng, S., Shi, J., \& Lou, G. (2007). A synergetic model for implementing an integrated an integrated management system: An empirical study in China. Journal of Cleaner Production, 15(18), 1760-1767. http://dx.doi.org/10.1016/j.jclepro.2006.03.007

Journal of Industrial Engineering and Management, 2015 (www.jiem.org)

(c)

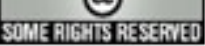

Article's contents are provided on a Attribution-Non Commercial 3.0 Creative commons license. Readers are allowed to copy, distribute and communicate article's contents, provided the author's and Journal of Industrial Engineering and Management's names are included. It must not be used for commercial purposes. To see the complete license contents, please visit http://creativecommons.org/licenses/by-nc/3.0/. 